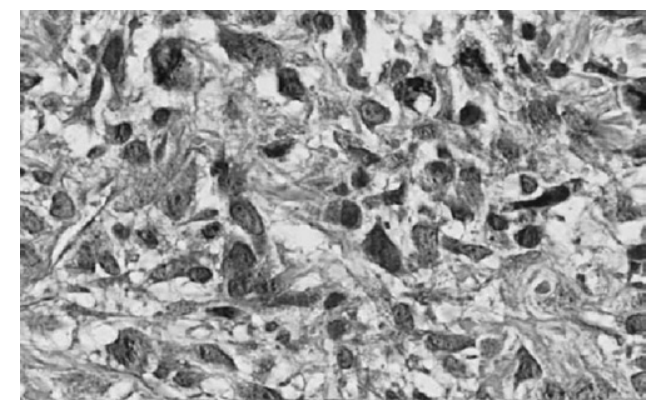

Figure 2. Histologic examination demonstrated pink islands of osteoid with malignant cells showing atypical mitosis. There was no identifiable epithelial component and no mesothelioma.

Metastatic disease is the commonest presentation of osteosarcoma in the chest, and primary pleural involvement without disease elsewhere is rare, although it has been previously reported. ${ }^{5}$ The clinical differential difficulties of primary pleural osteosar- coma include malignant pleural mesothelioma (histologic and radiologic), parosteal osteosarcoma of the rib, and osteosarcoma mimicking mesothelioma in pre-existing Paget disease of the bone. Fibrous mesothelioma with osseous metaplasia may represent another differential. It may be difficult to differentiate among these after extensive noninvasive investigations, but histologic examination increases the likelihood of confirming the diagnosis. Extraskeletal osteosarcomas are extremely malignant neoplasms, and recurrence and distant metastasis after resection are early features.

\section{References}

1. Bane BL, Evans HL, Ro JY, Carrasco CH, Grignon DJ, Benjamin RS, et al. Extraskeletal osteosarcoma: a clinicopathological review of 26 cases. Cancer. 1990;65:2762-70.

2. Wilson H. Extraskeletal ossifying tumours. Ann Surg. 1941;113:95-112.

3. Lee JSY, Fetsch JF, Wasdhal DA, Lee BP, Pritchard DJ, Nascimento AG. A review of 40 patients with extraskeletal osteosarcoma. Cancer. 1995;76:2253-9.

4. Colwell AS, D'Cunha J, Vargas SO, Parker B, Cin PD, Maddaus MA. Synovial sarcoma of the pleura: a clinical and pathologic study of three cases. J Thorac Cardiovasc Surg. 2002;124:828-32.

5. Stark P, Smith DC, Watkins GE, Chun KE. Primary intrathoracic extraosseous osteogenic sarcoma: report of 3 cases. Radiology. 1990;174:725-6.

\title{
Harm from seat belt: Transthoracic lung herniation and pericardial rupture
}

\author{
Christoph Benckert, MD, ${ }^{a}$ Armin Thelen, MD, ${ }^{a}$ Robert Pfitzmann, MD, ${ }^{a}$ Bernhard Gebauer, MD, ${ }^{b}$ Antonino Spinelli, MD, \\ Sven Jonas, MD, and Peter Neuhaus, MD, ${ }^{a}$ Berlin, Germany
}

T raumatic rib and sternal fractures mostly occur in association with seat belts in car crashes without airbag deployment. ${ }^{1}$ Lung herniation and pericardial rupture are rare concomitant injuries. ${ }^{2,3}$ We report a case of traumatic extrathoracic herniation of the lung and pericardial rupture as a consequence of multiple rib fractures and sternal dislocation in a seat belted passenger in a high-velocity car crash.

\footnotetext{
From the Departments of General, Visceral and Transplantation Surgery and Radiology, ${ }^{\mathrm{b}}$ Charité, Campus Virchow, Universitätsmedizin Berlin, Berlin, Germany.

Received for publication Aug 24, 2006; accepted for publication Sept 25, 2006.

Address for reprints: Christoph Benckert, MD, Department of General, Visceral and Transplantation Surgery, Charité, Campus Virchow Klinikum, Universitätsmedizin Berlin, Germany, Augustenburger Platz 1, 13353 Berlin, Germany (E-mail: christoph.benckert@ charite.de).

J Thorac Cardiovasc Surg 2007;133:588-9

$0022-5223 / \$ 32.00$

Copyright $\odot 2007$ by The American Association for Thoracic Surgery doi:10.1016/j.jtcvs.2006.09.066
}

\section{Clinical Summary}

A 79-year-old woman was involved in a severe car crash while sitting in the back seat. Clinical examination in the emergency department showed a left flail chest with subcutaneous emphysema and a massive hematoma left lateral to the sternum. Conventional chest radiography revealed that both lungs were expanded, with bilateral areas of hyperlucency (Figure 1,A). Multislice computed tomography revealed pneumomediastinum (Figure 1, $B$ ), bilateral lung contusion, hemothorax, and a herniation of segment 3 of the left lung through a large anterior apical chest wall defect (Figure 1, C), caused by segmented fractures of ribs 1 to 5 and a sternal body fracture. The endotracheal tube was switched to a double-lumen tube, and the patient was moved to the operating room, where left posterolateral thoracotomy was performed. The left lung was deflated for adequate exploration. At inspection, the lung had spontaneously retracted to the pleural cavity, and ribs 1 through 5 were fractured multiply at the chondrosternal junctions and along the anterior axillary line. A pericardial rupture was seen at the apical portion as a result of sternal dislocation without luxation of the heart. The pericardium was left open to reduce the risk of constrictive cardiogenic shock by pericardial effusion. The ruptured internal thoracic artery was ligated. A polytetrafluoroethylene mesh (Dualmesh; W. L. Gore \& Associates, Inc, Flagstaff, Ariz) was fixed to the pleura between the intact parts of the ribs lateral 


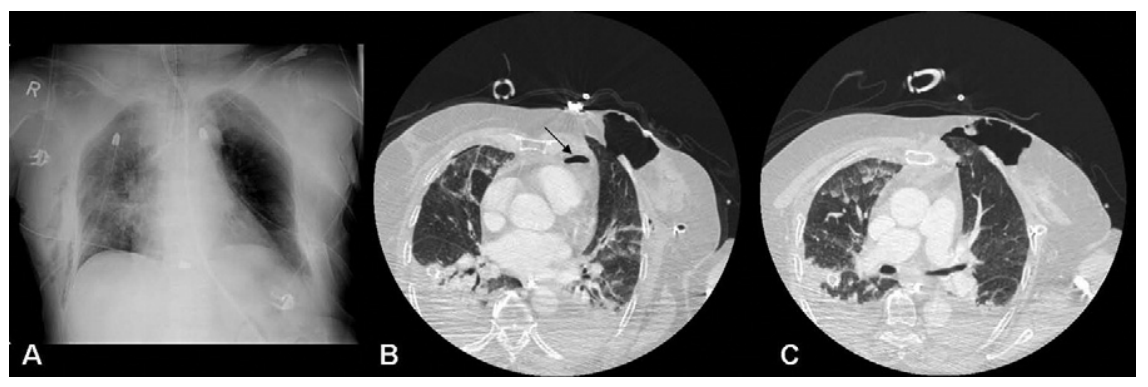

Figure 1. (A) Chest radiograph showing subcutaneous emphysema and hyperlucency from lung contusion and multiple rib fractures. (B) Multislice computed tomography showing pneumomediastinum (arrow) as indirect sign for pericardial rupture and (C) herniation of segment 3 of left lung through large anterior apical chest wall defect.

to the anterior axillary line and the sternum medially with interrupted 1-0 polypropylene sutures. Chest computed tomography performed on postoperative day (POD) 2 showed reintegration of the herniated lung and the mesh fitting to the anterior apical thoracic wall (Figure 2). The patient was extubated on POD 2. The further postoperative course was complicated by pneumonia; however, reintubation was not necessary. The chest tubes were removed on POD 20. Finally, the patient was discharged with no pain medication on POD 28.

\section{Discussion}

Seat belt use is recommended mainly to prevent head injuries in severe car crashes. It may, however, cause typical injuries to the lumbar or cervical spine, abdominal contents, or all three, known as seat belt syndrome. Airbag use is recommended to prevent rib, clavicle, or sternal fractures. In this case the use of the seat belt without airbag deployment led to an unstable left thoracic wall with sternal fracture, pericardial rupture, and lung herniation. Among 267 sternal fractures reported, ${ }^{1}$ most were located in the corpus sterni of seat-belted drivers injured in car crashes in old cars without airbags. Multiple rib fractures, lung contusions, and spinal injuries are the most frequent concomitant injuries. ${ }^{1}$ Pericardial rupture and lung herniation occur rarely. In future they may be diagnosed more often as a consequence of the more liberal use

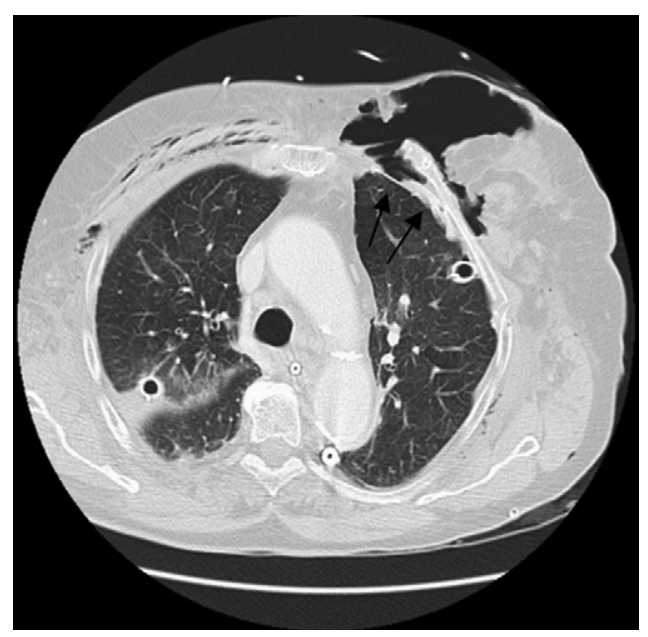

Figure 2. Multislice computed tomographic image showing reintegration of herniated lung and mesh fitting (arrows) to anterior apical thoracic wall. of multislice computed tomography. ${ }^{2}$ As reported in this case, clinical symptoms and conventional radiography may not reveal lung herniation. Multislice computed tomography showed lung herniation but failed to demonstrate the pericardial rupture, although the pneumomediastinum served as an indicator.

Pericardial ruptures may be left open if heart luxation seems unlikely, as in this case, or the pericardial sac may be partly covered with loose stitches to prevent existing or impending luxation of the heart. ${ }^{3}$

Lung herniations are well described and occur mostly at the anterior part of the chest wall, presumably because a lack of muscular support. Although small herniations have been managed conservatively, most lung hernias require surgery, because they do not resolve spontaneously and complications such as incarceration should be prevented. Small defects may be closed by transcostal rib fixation, but there is a great risk of hernia recurrence. ${ }^{4}$ Larger defects require either complex meshing by muscular flaps or a prosthetic mesh. Because of the large thoracic wall hematoma and extended thoracic wall emphysema in this case, a muscular flap did not seem appropriate, and the mesh was applied rapidly through a posterolateral thoracotomy, reducing the risk of thoracic wall infection. As an alternative approach to open thoracotomy, hernia repair with videoassisted thoracoscopic techniques may be performed. ${ }^{5}$

\section{Conclusion}

For traumatic transthoracic lung herniation, open or thoracoscopic implantation of surgical mesh is suggested, because it is rapidly applicable and shows favorable perioperative and late results.

\section{References}

1. Knobloch K, Wagner S, Haasper C, Probst C, Krettek C, Otte D, et al. Sternal fractures occur most often in old cars to seat-belted drivers without any airbag often with concomitant spinal injuries: clinical findings and technical collision variables among 42,055 crash victims. Ann Thorac Surg. 2006;82:444-50.

2. Arslanian A, Oliaro A, Donati G, Filosso PL. Posttraumatic pulmonary hernia. J Thorac Cardiovasc Surg. 2001;122:619-21.

3. Dato GM, Arslanian A, Filosso PL, Aidala E, Adduci M, Bardi G, et al. Heart herniation after blunt chest trauma. J Thorac Cardiovasc Surg. 2002;123:367-8.

4. Szentkereszty Z, Boros M, Sapy P, Kiss SS. Surgical treatment of intercostal hernia with implantation of polypropylene mesh. Hernia. 2006;10:354-6.

5. Reardon MJ, Fabre J, Reardon PR, Baldwin JC. Video-assisted repair of a traumatic intercostal pulmonary hernia. Ann Thorac Surg. 1998;65: 1155-7. 